\title{
Hypoxia-like tissue injury and glial response contribute to Balo concentric lesion development OPEN
}

Yoshiki Takai, MD, PhD

Tatsuro Misu, MD, PhD

Shuhei Nishiyama, MD,

$\mathrm{PhD}$

Hirohiko Ono, MD

Hiroshi Kuroda, MD,

$\mathrm{PhD}$

Ichiro Nakashima, MD,

$\mathrm{PhD}$

Ryuta Saito, MD, PhD

Masayuki Kanamori,

$\mathrm{MD}, \mathrm{PhD}$

Yukihiko Sonoda, MD, $\mathrm{PhD}$

Toshihiro Kumabe, MD, $\mathrm{PhD}$

Shunji Mugikura, MD, $\mathrm{PhD}$

Mika Watanabe, MD, PhD

Masashi Aoki, MD, PhD

Kazuo Fujihara, MD,

$\mathrm{PhD}$

Correspondence to

Dr. Aoki:

aokim@med.tohoku.ac.jp

\section{ABSTRACT}

Objective: To clarify the pathogenic factors and mechanisms underlying the development of concentric demyelinating lesions in Balo disease.

Methods: We conducted serial clinical, MRI, and histopathologic assessments of concentric lesion formation in a case of relapsing Balo disease.

Results: The patient experienced 2 attacks caused by left parietal and left frontal lesions in 5 years. In MRI findings from both episodes of expanding lesions, there were diffusion-restricted rings that antedated the appearance of gadolinium enhancement; subsequently, typical concentric T2 lesions appeared concurrently with the disappearance of this enhancement. Histopathologic examinations of biopsied brain tissues revealed definite concentric demyelinating layers typical of Balo disease with massive macrophage infiltration but preserved axons. Numerous hypertrophic astrocytes were observed beyond the edges of and within the demyelinating layers. The expression of hypoxiainducible factor- $1 \alpha$, a protein related to hypoxia-induced tissue preconditioning that contributes to survival and protection against further hypoxia-like injury, was upregulated primarily in glial cells located beyond the edge of the demyelinating layers but was also elevated in hypertrophic astrocytes on the inner sides of resected lesions and in oligodendrocytes in nondemyelinating layers. In addition, these astrocytes expressed CC motif chemokine 2 and/or interleukin-1 $\beta$, which are inducible by hypoxia-inducible factor- $1 \alpha$ and potentially promote demyelination.

Conclusions: Our study suggests that a unique interplay between hypoxia-induced tissue preconditioning and proinflammatory cytokines derived from glial cells may contribute to the development of concentric demyelinating lesions in Balo disease. Neurology ${ }^{\circledR}$ 2016;87:2000-2005

\section{GLOSSARY}

BCS $=$ Balo concentric sclerosis; CCL2 = CC motif chemokine 2; CCR2 = CC chemokine receptor type 2; HIF-1 $\alpha=$ hypoxiainducible factor- $1 \alpha ; \mathbf{I L - 1} \boldsymbol{\beta}=$ interleukin-1 $\beta$.

Balo concentric sclerosis (BCS), which was first described in 1928, is characterized by distinct alternating demyelinating rings. Brain MRI examinations of BCS reveal a distinct pattern of isointense and hyperintense rings that correspond to bands of preserved and destroyed myelin, respectively. MRI has also provided important information on the pathology of BCS; in particular, MRI results have indicated a gradient of decreasing perfusion from the center to the periphery of lesions, significant elevations of lactate at the periphery of lesions, and restricted diffusion at early stages of the disease. These findings suggest that hypoxic events may contribute to the pathogenesis of BCS. ${ }^{1}$

A previous histopathologic study revealed hypoxia-like tissue injury in active demyelinating lesions in BCS and the upregulation of ischemic tissue-preconditioning proteins such as hypoxia-inducible factor- $1 \alpha(\mathrm{HIF}-1 \alpha)$ at the periphery of BCS lesions. ${ }^{2}$ This report concluded that preserved myelin in

From the Departments of Neurology (Y.T., T.M., S.N., H.O., H.K., I.N., M.A., K.F.), Multiple Sclerosis Therapeutics (T.M., K.F.), Neurosurgery (R.S., M.K.), Diagnostic Radiology (S.M.), and Pathology (M.W.), Tohoku University Graduate School of Medicine, Sendai; Department of Neurology (T.M.), National Hospital Organization Hachinohe National Hospital; Department of Neurosurgery (Y.S.), Yamagata University School of Medicine; and Department of Neurosurgery (T.K.), Kitasato University School of Medicine, Kanagawa, Japan.

Go to Neurology.org for full disclosures. Funding information and disclosures deemed relevant by the authors, if any, are provided at the end of the article. The Article Processing Charge was paid by the authors.

This is an open access article distributed under the terms of the Creative Commons Attribution-NonCommercial-NoDerivatives License 4.0 (CC BY-NC-ND), which permits downloading and sharing the work provided it is properly cited. The work cannot be changed in any way or used commercially. 


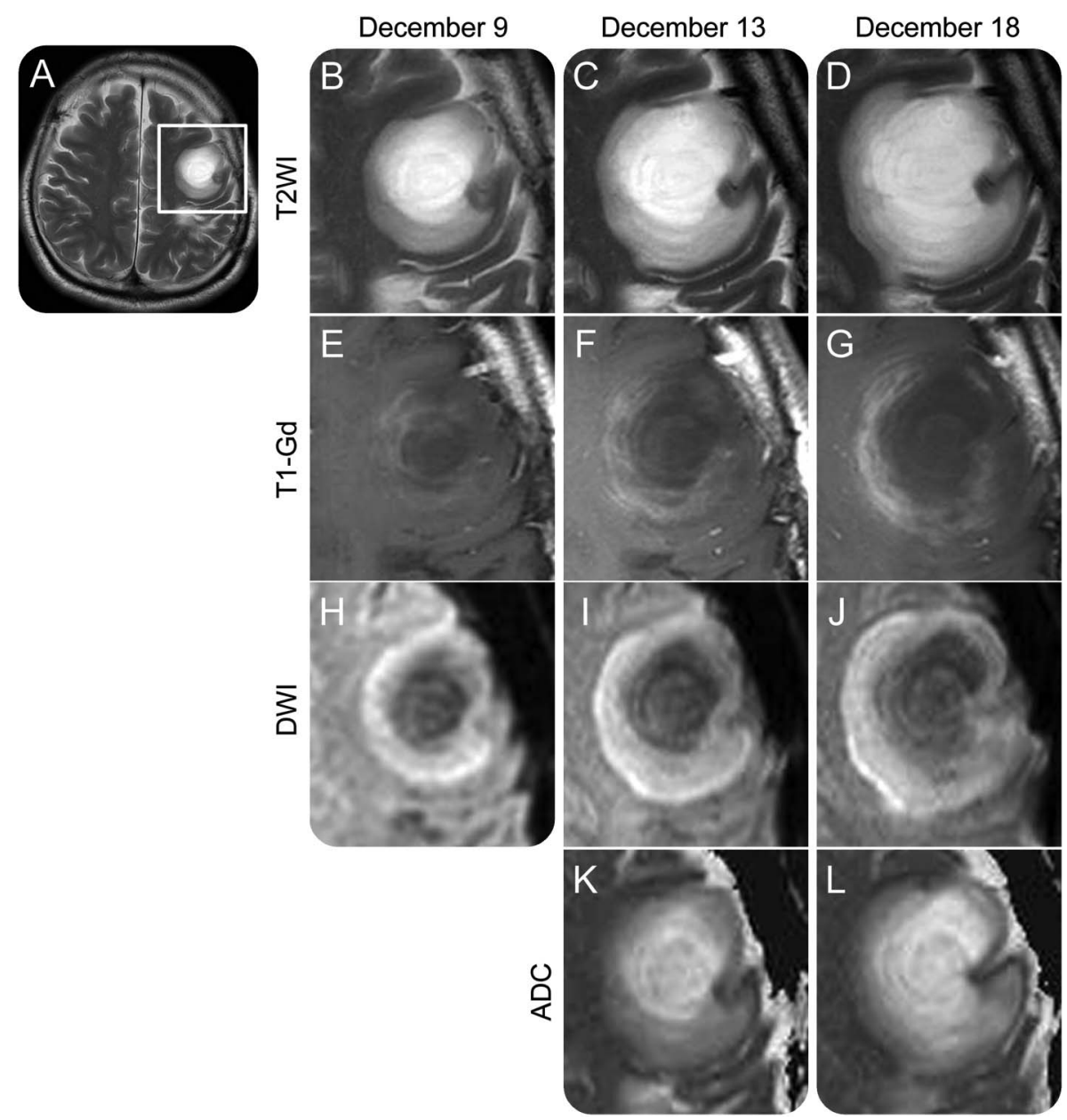

Images from the patient's second episode, obtained on December $9(\mathrm{~A}, \mathrm{~B}, \mathrm{E}$, and $\mathrm{H})$, December $13(\mathrm{C}, \mathrm{F}, \mathrm{I}$, and $\mathrm{K})$, and December 18 (D, G, J, and L) in 2015. (A) T2-weighted images (T2WIs) clearly depicted concentric lesions in the left frontal lobe. (B-L) Magnified images of the left frontal lobe depicted in (A) (rectangle). (B-D) T2WI revealed concentric patterns made by hyperintense and isointense rings in the lesion core, which was surrounded by regions with slightly elevated signal intensity. Both the core and peripheral regions of the lesion expanded in a concurrent manner (T2WI). (E-G) Gadolinium (Gd)enhanced lesions were located only around the lesion core and were even detected in areas with uniform intensity in T2WI (post-Gd T1-weighted images [T1-Gd]). (H-J) Diffusion-weighted images (DWIs) exhibited high intensities in the peripheral regions beyond Gd-enhanced lesions. (K-L) Apparent diffusion coefficient (ADC) values gradually decreased from the center to the periphery of the lesion in a concentric manner (ADC map).

BCS consisted of tissue-preconditioned oligodendrocytes that survived additional hypoxialike injury. ${ }^{2}$ However, a hypothesis based on mathematical modeling of Liesegang ring formation suggests that the preconditioning theory alone may be insufficient to produce concentric rings with realistic diameters. ${ }^{3}$ Thus, researchers have speculated that both activating agents (currently unidentified) and protective agents such as tissue-preconditioning proteins might be necessary for the development of concentric rings in BCS; however, this theory has not been examined.

To address the aforementioned issues, we analyzed serial MRI and histopathologic findings from biopsied brain tissues obtained from a case of relapsing BCS.

METHODS Neuropathologic analysis. Biopsied left parietal lesions were processed for paraffin-embedded to standard procedures. Immunohistochemical analysis and ultrastructural examination of the sample were performed as previously described. ${ }^{4}$

Standard protocol approvals, registrations, and patient consents. This study was approved by the Tohoku University Human Research Ethics Committee with written informed consent.

RESULTS Case. A 45-year-old Japanese man was admitted to a local hospital for gradually progressive numbness and muscle weakness in his right arm. A brain MRI revealed concentric T2-hyperintense 

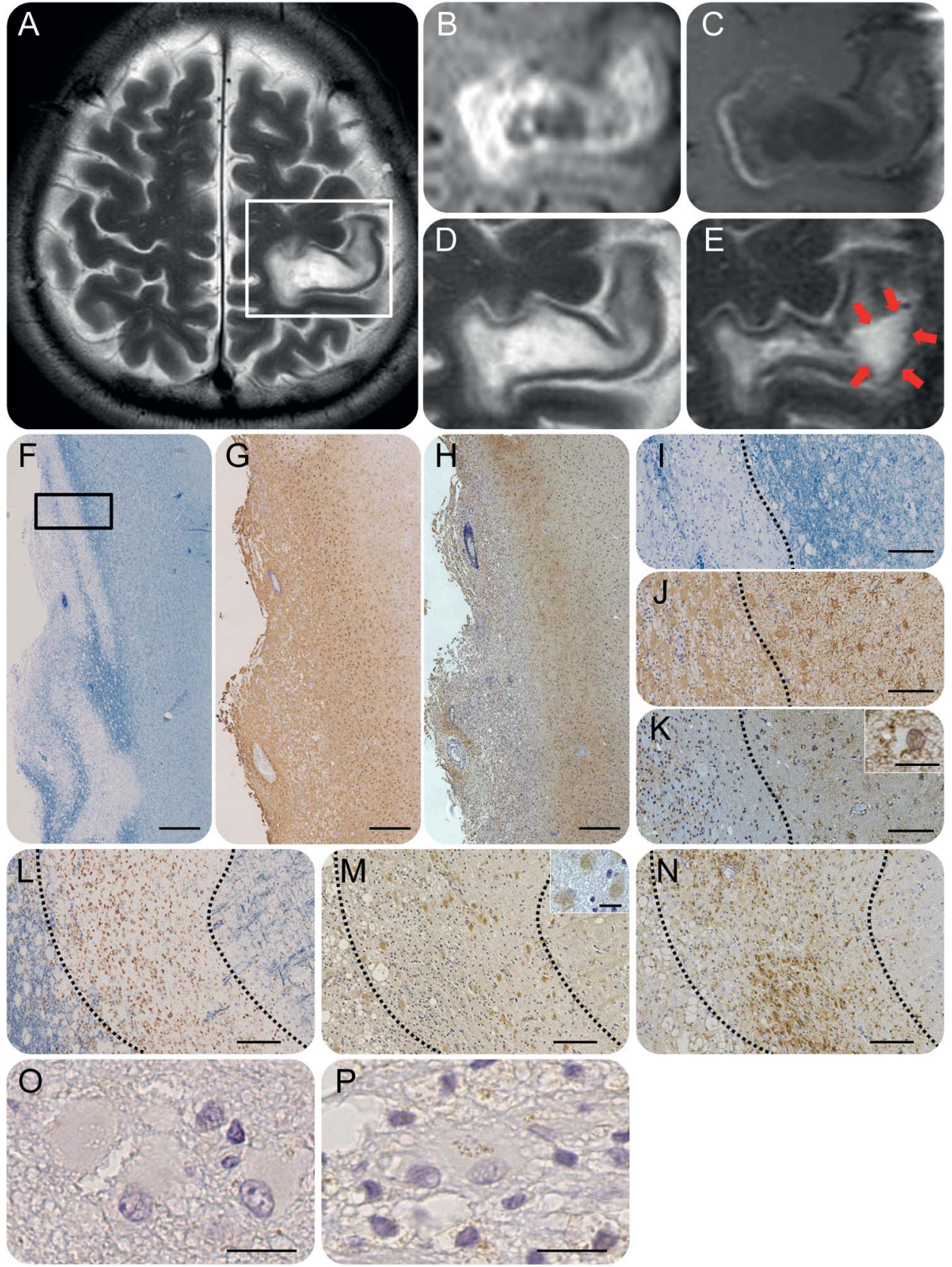

(A-D) Prebiopsy MRI; (E) postbiopsy MRI. (A) T2-weighted image (T2WI) revealed concentric lesions in the left parietal white matter. (B-D) Magnified images of the parietal lobe depicted in (A) (rectangle). MRI findings and the presence of peripheral diffusion-weighted image (DWI) hyperintense lesions with gadolinium enhancements at lesion edges were similar to the results obtained during the patient's relapse (B, DWI; C, postgadolinium T1-weighted image; $\mathrm{D}, \mathrm{T} 2 \mathrm{WI})$. (E) Postbiopsy MRI clearly indicated the resected area (red arrows) (T2WI). (F-P) histopathological findings for the biopsied brain (left parietal). $(\mathrm{F}-\mathrm{H}, \mathrm{I}-\mathrm{K}$, and L-N) Same areas, respectively. (F) Concentric demyelinating lesions were clearly recognizable by KlüverBarrera myelin staining (scale bar $=500 \mu \mathrm{m}$ ). (G) Glial fibrillary acidic protein (GFAP)-positive hypertrophic astrocytes were observed beyond the edge of the demyelinating layers (GFAP [brown], scale bar $=500 \mu \mathrm{m}$ ). (H) Hypoxia-inducible factor- $1 \alpha$ (HIF-1 $\alpha$ ) was upregulated around the outer edges of demyelinating lesions (HIF-1 $[$ [brown], scale bar $=500 \mu \mathrm{m})$. (I-K) Highmagnification images of a selected area depicted in (F) (rectangle). Dotted lines mark the border between demyelinated and myelinated layers. (I) Myelin staining clearly revealed the boundary of demyelinated and myelinated regions (Klüver-Barrera myelin staining, scale bar $=200 \mu \mathrm{m})$. $(\mathrm{J})$ Hypertrophic astrocytes were seen even in the nondemyelinating area. However, astrocytes were different morphologically in demyelinated and myelinated regions (balloon-shaped in the demyelinated area and star-shaped in the myelinated area; GFAP [brown], scale bar $=200 \mu \mathrm{m})$. (K) HIF-1 $\alpha$ upregulation was particularly prominent in hypertrophic astrocytes (HIF-1 1 [brown], scale bar $=200 \mu \mathrm{m}$ or $20 \mu \mathrm{m}$ in inset of a single astrocyte). (L) Numerous activated macrophages had infiltrated the demyelinating lesions (myelin basic protein [blue]/CD68 [brown], scale bar $=150 \mu \mathrm{m}$ ). (M) CC motif chemokine 2 (CCL2) expression was evident in the cytoplasm of hypertrophic astrocytes (inset, 
lesions with gadolinium-enhanced rings in the left parietal lobe. To exclude a brain tumor, an MRIguided open brain biopsy was performed. After this biopsy, the patient received low-dose betamethasone, and his symptoms gradually subsided. One month later, he was discharged with only mild right arm weakness.

Five years later, the patient was rehospitalized because of speech difficulties and right arm weakness. In a neurologic examination, he exhibited nonfluent aphasia and moderate right hemiparesis. A brain MRI revealed a new T2 concentric lesion with several alternating hyperintense and isointense rings in the left frontal lobe (figure 1). This lesion gradually expanded; its outermost hyperintense layer was visible in diffusion-weighted images. Apparent diffusion coefficient values were reduced only in the outermost layer of the diffusion-weighted image hyperintense lesion. Several gadolinium-enhanced rings were observed within the edge of the diffusion-restricted layer (figure 1, A-L). CSF examination revealed a high myelin basic protein level $(336 \mathrm{pg} / \mathrm{mL})$, but the oligoclonal band was negative. After rigorous diagnostic workup to exclude diagnoses such as neoplasms, infections, and systemic autoimmune diseases, the patient was diagnosed with BCS. Although 3 courses of high-dose intravenous methylprednisolone and monthly intravenous cyclophosphamide therapy did not improve his symptom, after intravenous immunoglobulin $(0.4 \mathrm{~g} / \mathrm{kg}$ for 5 days $\times 2$ courses $)$, he became able to move his right limbs, and gadolinium enhancement in the brain lesion was attenuated. His symptoms improved further thereafter.

Pathologic findings. Tissue samples were obtained from the lesion in the left postcentral gyrus at onset (figure 2, A-E). Subcortical white matter samples were spongy, suggesting brain edema. Many swollen eosinophilic astrocytes were present in the lesion, with a number of instances of perivascular cuffing. Concentric demyelinating lesions typical of Balo disease were observed; these lesions featured massive macrophage infiltration but preserved axons (figure 2, F and I). Many glial fibrillary acidic proteinpositive hypertrophic astrocytes were visible beyond the outer edges of the demyelinating layers (figure 2, $\mathrm{G}$ and J). At the outer edge of the demyelinating lesion and in surrounding normal-appearing white matter, HIF-1 $\alpha$, a key factor in tissue preconditioning, was upregulated. HIF- $1 \alpha$ was expressed mainly in glial cells; in particular, this protein was expressed by hypertrophic astrocytes (figure 2, $\mathrm{H}$ and $\mathrm{K}$ ). $\mathrm{CC}$ motif chemokine 2 (CCL2) and its receptor CC chemokine receptor type 2 (CCR2) were detected in active demyelinating lesions. CCL2 was expressed mainly in hypertrophic astrocytes, whereas CCR2 was detected in microglia and macrophages, which had infiltrated the demyelinating layers (figure 2, L-N). Aquaporin 4 was also detectable in active demyelinating lesions. In demyelinating lesions, interleukin-1 $\beta$ (IL-1 $\beta$ ) was found within foamy macrophages and, to a lesser degree, in hypertrophic astrocytes (figure 2, O-P).

DISCUSSION The present study of BCS is unique in that a detailed pathologic study of developing concentric demyelinating lesions was conducted, we could compare MRI data with neuropathologic findings for the BCS lesions, and serial MRIs of expanding brain lesions of BCS were available at onset and relapse. Diffusion-restricted areas initially formed at lesion edges; subsequently, gadolinium-enhanced layers formed at the inner aspect of the initial lesions. These gadolinium-enhanced layers gradually lost their enhancement and became T2 hyperintense, which indicated that demyelination was occurring. These changes were accompanied by the outward emergence of new diffusion-restricted layers. The repetition of these processes led to the development of concentric rings characteristic of BCS. In addition, concentric demyelinating layers typical of BCS were histologically confirmed, and the expression of tissue preconditioning-related proteins was observed at the rim of periplaque regions, consistent with previously reported results. ${ }^{2}$ These findings indicated that a hypoxia-like event preceded demyelinating processes in BCS.

Those investigators hypothesized that this hypoxialike tissue preconditioning would play a major role in causing concentric demyelination in BCS. Although this tissue preconditioning-based theory focuses on tissue protection mechanisms, the mechanisms by which BCS lesions expand have remained unclear. Moreover, they reported that oligodendrocytes were the main source of HIF-1 $\alpha,{ }^{2}$ whereas our findings indicated that astrocytes also abundantly expressed tissue preconditioning-related proteins in the outermost layer of concentric BCS lesions.

HIF- $1 \alpha$ is a transcription factor that regulates cellular responses to hypoxia. Although HIF- $1 \alpha$

Figure 2 legend, continued:

scale bar $=20 \mu \mathrm{m}$ ), which were located mainly in peripheral demyelinating layers (CCL2 [brown], scale bar $=150)$. (N) Infiltrating cells (microglia and macrophages) in demyelinating layers expressed CC chemokine receptor type 2 (CCR2),

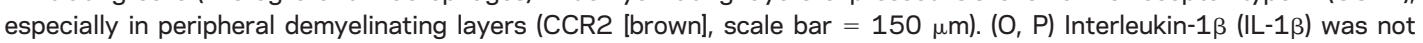
expressed in myelinated layers (O). However, in the demyelinating lesions, II-1 $\beta$ expression was detected in macrophages and, to a lesser extent, in hypertrophic astrocytes (P) (IL-1 [brown], scale bar $=20 \mu \mathrm{m})$. 
expression in neurons prevents hypoxia-induced neuronal cell death, HIF- $1 \alpha$ expression in astrocytes enhances neuronal cell death if both types of cells are cocultured. ${ }^{5}$ These HIF- $1 \alpha$-induced bystander effects of astrocytes could influence oligodendrocytes and may be associated with concentric lesion formation in BCS. The genes for both IL-1 $\beta$ and CCL2 carry multiple HIF-1 binding sites in their promoter regions and exhibit expression that is upregulated by hypoxia in astrocytes via HIF- $1 \alpha$ expression. ${ }^{6,7}$ IL-1 $\beta$ is a proinflammatory cytokine that may be associated with the progression of multiple sclerosis, ${ }^{8}$ and chronic IL-1 $\beta$ expression can induce reversible demyelination. ${ }^{9}$ In addition, elevated CCL2 expression has been detected in acute and chronic multiple sclerosis plaques, particularly in hypertrophic astrocytes. ${ }^{10}$ CCL2 is a chemotactic factor of $\mathrm{T}$ cells and macrophages, which exhibited massive infiltration into the BCS lesions examined in this study. We detected hypertrophic astrocytes that expressed IL-1 $\beta$ and CCL2 in lesions and CCR2-positive macrophages in demyelinating layers. Simply stated, HIF1- $\alpha$-expressing astrocytes in tissue-preconditioned layers may secrete the 2 aforementioned proinflammatory cytokines and induce demyelination via IL-1 $\beta$-induced tissue injury and the recruitment of pathogenic $\mathrm{T}$ cells and activated macrophages by CCL2, whereas HIF1- $\alpha-$ expressing oligodendrocytes in layers that have been subjected to tissue preconditioning may experience relatively little cellular damage. The MRI and pathologic findings in our case strongly suggest that hypoxia-like processes precede inflammation and demyelination in BCS and that tissue preconditioning and astrocyte-derived proinflammatory cytokines may contribute to producing a unique tissuedamage pattern that leads to the formation of concentric lesions. These pathologic findings should be confirmed in larger-scale analyses.

\section{AUTHOR CONTRIBUTIONS}

Y.T.: analyzed the data and wrote the paper. Substantial contribution to the study conception, acquisition, analysis, and interpretation of data for the work, writing the manuscript, drafting and correction of all versions of the manuscript including figures, tables, and references. Completion of the work to be submitted. Final approval of the version to be published. Agreement to be accountable for all aspects of the work. T.M.: substantial contribution to the conception and design of the work, as well as supervision of the acquisition, analysis, and interpretation of data for the work. Revising several versions of manuscript critically for important intellectual content. Final approval of the version to be published. Agreement to be accountable for all aspects of the work. S.N.: contribution to the plan of the work, acquisition, analysis, interpretation of data for the work, and drafting the original manuscript related to case. Final approval of the version to be published. Agreement to be accountable for all aspects of the work. H.O.: acquisition, analysis, and interpretation of data for the work. Final approval of the version to be published. Agreement to be accountable for all aspects of the work. H.K.: acquisition, analysis, and interpretation of data for the work. Revising of manuscript critically for important intellectual content. Final approval of the version to be published. Agreement to be accountable for all aspects of the work. I.N.: analysis and interpretation of data for the work. Revising of manuscript critically for important intellectual content. Final approval of the version to be published. Agreement to be accountable for all aspects of the work. R.S., M.K., Y.S., and T.K.: acquisition, analysis, and interpretation of data for the work. Final approval of the version to be published. Agreement to be accountable for all aspects of the work. S.M.: substantial contribution to interpretation of data for the work, analysis and interpretation of data for the work. Final approval of the version to be published. Agreement to be accountable for all aspects of the work. M.W.: acquisition, analysis, and interpretation of data for the work. Final approval of the version to be published. Agreement to be accountable for all aspects of the work. M.A.: substantial contribution to the conception and design of the work, as well as supervision of the acquisition, analysis, and interpretation of data for the work. Final approval of the version to be published. Agreement to be accountable for all aspects of the work. K.F.: substantial contribution to the conception and design of the work, as well as supervision of the acquisition, analysis, and interpretation of data for the work. Supervision of the manuscript preparation. Revising several versions of manuscript critically for important intellectual content. Final responsibility and approval of the version to be published. Agreement to be accountable for all aspects of the work.

\section{ACKNOWLEDGMENT}

The authors thank Kayoko Hayashi for technical assistance.

\section{STUDY FUNDING}

This study was supported in part by KAKENHI (No. 15K19473, 26293205) of the Ministry of Education, Culture, Sports, Science and Technology of Japan.

\section{DISCLOSURE}

Y. Takai has received research support from a grant-in-aid for scientific research from the Ministry of Education, Culture, Sports, Science and Technology of Japan. T. Misu has received speaker honoraria from Bayer Schering Pharma, Biogen Idec Japan, Mitsubishi Tanabe Pharma Corp, Asahi Kasei Medical Co, and Astellas Pharma Inc and has received research support from Bayer Schering Pharma, Biogen Idec Japan, Asahi Kasei Kuraray Medical Co, The Chemo-Sero-Therapeutic Research Institute, Teva Pharmaceutical K.K., Mitsubishi Tanabe Pharma Corp, and Teijin Pharma, and grants-in-aid for scientific research from the Ministry of Education, Culture, Sports, Science and Technology, and the Ministry of Health, Labor and Welfare of Japan. S. Nishiyama has received research support from a grant-in-aid for scientific research from the Ministry of Education, Culture, Sports, Science and Technology of Japan. H. Ono reports no disclosures relevant to the manuscript. H. Kuroda has received research support from a grant-in-aid for scientific research from the Ministry of Education, Culture, Sports, Science and Technology of Japan. I. Nakashima has received funding for travel, speaker honoraria from Tanabe Mitsubishi Pharma Corp, research funding from LSI Medience Corp, and grants-in-aid for scientific research from the Ministry of Education, Culture, Sports, Science and Technology of Japan. R. Saito, M. Kanamori, and Y. Sonoda has received research support from a grant-in-aid for scientific research from the Ministry of Education, Culture, Sports, Science and Technology of Japan. T. Kumabe has received speaker honoraria from Eisai Co., Ltd and has received research support from grants-in-aid for scientific research from the Ministry of Education, Culture, Sports, Science and Technology, and the Ministry of Health, Labor and Welfare of Japan. S. Mugikura has received research support from a grant-in-aid for scientific research from the Ministry of Education, Culture, Sports, Science and Technology of Japan. M. Watanabe reports no disclosures relevant to the manuscript. M. Aoki has received research support from grants-in-aid for scientific research from the Ministry of Education, Culture, Sports, Science and Technology, and the Ministry of Health, Labor and Welfare of Japan. K. Fujihara serves on scientific advisory boards for Bayer Schering Pharma, Biogen Idec, Mitsubishi Tanabe Pharma Corp, Novartis Pharma, Chugai Pharmaceutical, Ono Pharmaceutical, Nihon Pharmaceutical, Merck Serono, Alexion Pharmaceuticals, Medimmune and Medical Review; has received funding for 
travel and speaker honoraria from Bayer Schering Pharma, Biogen Idec, Eisai Inc, Mitsubishi Tanabe Pharma Corp, Novartis Pharma, Astellas Pharma Inc, Takeda Pharmaceutical Co Ltd, Asahi Kasei Medical Co, Daiichi Sankyo, and Nihon Pharmaceutical; serves as an editorial board member of Clinical and Experimental Neuroimmunology (2009present) and an advisory board member of Sri Lanka Journal of Neurology; has received research support from Bayer Schering Pharma, Biogen Idec Japan, Asahi Kasei Medical, The Chemo-Sero-Therapeutic Research Institute, Teva Pharmaceutical, Mitsubishi Tanabe Pharma, Teijin Pharma, Chugai Pharmaceutical, Ono Pharmaceutical, Nihon Pharmaceutical, and Genzyme Japan; and is funded by grants-in-aid for scientific research from the Ministry of Education, Culture, Sports, Science and Technology of Japan (No. 22229008, 2010-2015; No. 26293205, 2014-2016) and by grants-in-aid for scientific research from the Ministry of Health, Welfare and Labor of Japan (2010-present). Go to Neurology.org for full disclosures.

Received October 15, 2015. Accepted in final form July 27, 2016.

\section{REFERENCES}

1. Mowry EM, Woo JH, Ances BM. Technology insight: can neuroimaging provide insights into the role of ischemia in Balo's concentric sclerosis? Nat Clin Pract Neurol 2007;3: 341-348.

2. Stadelmann C, Ludwin S, Tabira T, et al. Tissue preconditioning may explain concentric lesions in Balo's type of multiple sclerosis. Brain 2005;128:979-987.

3. Khonsari RH, Calvez V. The origins of concentric demyelination: self-organization in the human brain. PLoS One 2007;2:e150
4. Misu T, Fujihara K, Kakita A, et al. Loss of aquaporin 4 in lesions of neuromyelitis optica: distinction from multiple sclerosis. Brain 2007;130:1224-1234.

5. Vangeison G, Carr D, Federoff HJ, Rempe DA. The good, the bad, and the cell type-specific roles of hypoxia inducible factor-1 alpha in neurons and astrocytes. J Neurosci 2008;28:1988-1993.

6. Zhang W, Petrovic JM, Callaghan D, et al. Evidence that hypoxia-inducible factor-1 (HIF-1) mediates transcriptional activation of interleukin-1beta (IL-1beta) in astrocyte cultures. J Neuroimmunol 2006;174:63-73.

7. Mojsilovic-Petrovic J, Callaghan D, Cui H, Dean C, Stanimirovic DB, Zhang W. Hypoxia-inducible factor-1 (HIF-1) is involved in the regulation of hypoxia-stimulated expression of monocyte chemoattractant protein-1 (MCP-1/CCL2) and MCP-5 (Ccl12) in astrocytes. J Neuroinflammation 2007;4:12.

8. Reale M, de Angelis F, di Nicola M, et al. Relation between pro-inflammatory cytokines and acetylcholine levels in relapsing-remitting multiple sclerosis patients. Int J Mol Sci 2012;13:12656-12664.

9. Li Q, Powell N, Zhang H, et al. Endothelial IL-1R1 is a critical mediator of EAE pathogenesis. Brain Behav Immun 2011;25:160-167.

10. McManus C, Berman JW, Brett FM, Staunton H, Farrell M, Brosnan CF. MCP-1, MCP-2 and MCP-3 expression in multiple sclerosis lesions: an immunohistochemical and in situ hybridization study. J Neuroimmunol 1998;86:20-29.

\section{Applications Now Open for 2017 Diversity in Leadership Program}

Applications are now open for the prestigious 2017 AAN Diversity in Leadership Program, which seeks to identify, orient, and cultivate high-potential members from diverse and underrepresented ethnic backgrounds who will be lifetime, engaged contributors to the American Academy of Neurology. View qualifications and apply before the December 10 deadline at AAN.com/view/DiversityLeadershipProgram.

\section{Save These Dates for AAN CME Opportunities!}

Mark these dates on your calendar for exciting continuing education conferences by the American Academy of Neurology. Learn more at AAN.com/conferences.

\section{Breakthroughs in Neurology}

- January 13-16, 2017, Phoenix, AZ, at the Sheraton Grand at Wild Horse Pass

\section{AAN Annual Meeting}

- April 22-28, 2017, Boston, MA, at the Boston Convention Center 


\section{Neurology}

\section{Hypoxia-like tissue injury and glial response contribute to Balo concentric lesion development}

Yoshiki Takai, Tatsuro Misu, Shuhei Nishiyama, et al.

Neurology 2016;87;2000-2005 Published Online before print October 12, 2016

DOI 10.1212/WNL.0000000000003308

This information is current as of October 12, 2016

\begin{tabular}{|c|c|}
\hline $\begin{array}{l}\text { Updated Information \& } \\
\text { Services }\end{array}$ & $\begin{array}{l}\text { including high resolution figures, can be found at: } \\
\text { http://n.neurology.org/content/87/19/2000.full }\end{array}$ \\
\hline References & $\begin{array}{l}\text { This article cites } 10 \text { articles, } 1 \text { of which you can access for free at: } \\
\text { http://n.neurology.org/content/87/19/2000.full\#ref-list- } 1\end{array}$ \\
\hline Citations & $\begin{array}{l}\text { This article has been cited by } 1 \text { HighWire-hosted articles: } \\
\text { http://n.neurology.org/content/87/19/2000.full\#\#therarticles }\end{array}$ \\
\hline Subspecialty Collections & $\begin{array}{l}\text { This article, along with others on similar topics, appears in the } \\
\text { following collection(s): } \\
\text { All Demyelinating disease (CNS) } \\
\text { http://n.neurology.org/cgi/collection/all_demyelinating_disease_cns }\end{array}$ \\
\hline Permissions \& Licensing & $\begin{array}{l}\text { Information about reproducing this article in parts (figures,tables) or in } \\
\text { its entirety can be found online at: } \\
\text { http://www.neurology.org/about/about_the_journal\#permissions }\end{array}$ \\
\hline Reprints & $\begin{array}{l}\text { Information about ordering reprints can be found online: } \\
\text { http://n.neurology.org/subscribers/advertise }\end{array}$ \\
\hline
\end{tabular}

Neurology ${ }^{\circledR}$ is the official journal of the American Academy of Neurology. Published continuously since 1951, it is now a weekly with 48 issues per year. Copyright () 2016 American Academy of Neurology. All rights reserved. Print ISSN: 0028-3878. Online ISSN: 1526-632X.

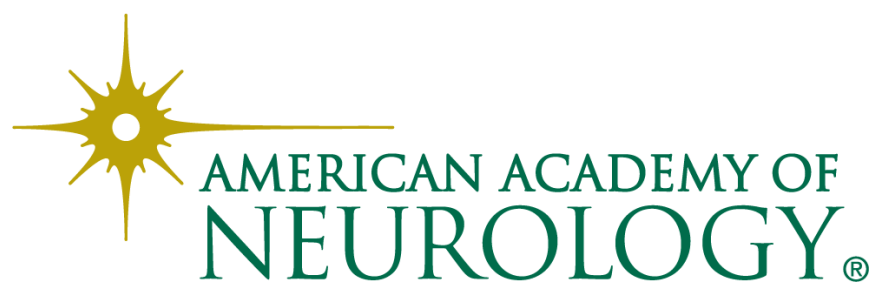

